hensive "Pre-Historic Man," which has reached a second edition, he has already paid a good deal of attention to the Huron tribe, as well as to other tribes of the North American Indians, which, in fact, constitutes one great feature of value in the work.

In this volume Dr. Wilson gave a table of the measurements of thirty-seven Huron skulls "obtained from Indian graves to the north of the water-shed between Georgian Bay and Lakes Erie and Ontario." The great purpose of the construction of this table, as of so many other investigations made by the author, was to test the truth of a doctrine which had been generally reccived and was in great measure endorsed by Dr. S. G. Morton, who produced the classical "Crania Americana." This doctrine, in few words, is that the American race is almost uniform in its head characters from one end of the continent to the other, and that the American typical cranium is distinguished for its shortness. To Dr. D. Wilson's persevering researches we must allow the merit of having shown that there is much variety in native American races, and that in their skulls there is considerable diversity of length. This may be very confidently asserted, without conceding to him an agreement with his assertions respecting the long skulls among the ancient Peruvians ; for he evidently mistook the deformed crania of these people for the representatives of the natural form of their heads.

In the table of the measurements of thirty-seven human skulls referred to, it was seen that their length varied much. If we exclude the "Barrie skull," No. 23, which appears to be quite aberrantly short, and it is thought has been distorted by art, we find their longitudinal diameter to vary from $7^{\circ} 9$ inches to 6.8 inches, or above an inch. The cephalic indices of these two examples, unfortunately, cannot be accurately calculated from Dr. Wilson's measurements. One of his items of measurement is "F. D." frontal diameter, which he says in this memoir " is taken from the point of junction of the frontal, parietal, and malar bones." This latter is probably an inadvertence, and should be sphenoidal bone, as the malar bone nowhere joins the frontal.

Since this table was constructed, thanks to the efforts of Dr. Taché and others, Dr. Wilson has had the opportunity of measuring many more Huron skulls. He now says : "The sight of upwards of seventy skulls, all derived from the cemeteries of a single tribe or nation, is a peculiarly interesting study to the ethnologist. But to one at all impressed with the uniform persistency of a specific ethnical type, the result is far from satisfactory." They are seen to vary materially, and especially in length. The skulls of women present a decided projection of the occiput, and here we may be permitted to allude to Dr. Wilson's plates. The first, which gives shaded profile views of the calvaria of a Huron man and woman, is excellent and very characteristic. Plate II. is lettered, "Long Huron skull, male." It is often very difficult to determine positively the sex in crania, but in this example it seems doubtful whether the plate does not exhibit the calvarium of a woman. We incline to think that it does. The long oval, vertical view is quite apparent and unquestionable. Plate III. is an undoubted instance of a "Long Huron skull, male."

Dr. Wilson, after attesting the great range of diversities in the Huron skulls he has seen, concludes in these noticeable terms: "But the specialties of the whole, in their front aspect, suggest a greater uniformity in their physiognomy than in cranial conformation. The nose is in most cases large and prominent; the superciliary ridges in the males are strongly developed; and a common ethnical character may be traced in the full-face as a whole, including the massive broad cheek-bones and superior maxilla ; as well as in the indications in the greater number of a tendency towards a pointed apex, or meeting of the parietal bones at an angle at the sagittal suture." Perhaps this is as much as anyone can reasonably expect, even when divergences are to be acknowledged in the proper calvarial form. And it is difficult to conceive that these divergences are so utter and so puzzling as to prevent our seeing any constancy among them.

Dr. Wilson, in showing that some tribes of American Indians are characterised by long or dolichocephalic heads, still admits that other tribes have short or brachycephalic heads. This must be conceded, as well as that Morton's generalisation was too comprehensive and too literal. Former sweeping conclusions as to dolichocephaly and brachycephaly cannot now be sustained. It was long since seen that among the crania of any extended race of people, as the ancient Britons, there is much variation as to length, indeed that a scale might be exhibited from the shortest to the longest, in which the numerous intermediate lengths intervene to fill up the ascending degrees of the range. This truth is now more than ever apparent, since the elaborate researches among the skulls of Italian races by the distinguished anatomist, Prof. Luigi Calori, of Bologna. He has conclusively shown that there is much more dolichocephaly among the races of Italy than was previously known.

Much of the difficulty that craniologists have encountered in the study of the head-forms of different races, has had its foundation in the too rigid rules which they have assumed these forms to observe. Dr. Wilson's labours have served well to illustrate this point in reference to the American races. Were this the proper place, it would be easy to point to examples of the futile labours which have resulted from these self-imposed rules. How many learned controversies have been entertained to determine the race of a man whose only existing relic was his lower jaw? On finding that such rules cannot be fixed and defined in so absolute a manner, it has often been the case that other inquirers have lost confidence in craniology itself. This is a transition from one extreme to another. More moderate expectations from the doctrine of skull. forms would have prevented confidence in their value from being so often shaken. Larger views must be taken, but these are quite compatible with our knowledge, without any necessary leaning to the meanderings of the evolutionary hypotheses alluded to by our author.

\section{CONDUCTIVITY OF MERCURY}

$\mathrm{T} T$ was shown in a previous article * that solar intensity 1 cannot be accurately ascertained by the thermoheliometer employed by Père Secchi, owing, among other causes, to the imperfect conductivity of the mercury in the bulb exposed to the sun. Meteorologists, however, do not generally accept the assumption that the conducting power of mercury is so imperfect as to affect materially the correctness of the indication of mercurial thermometers, Deschanel being quoted in support of the opinion that mercury is not an imperfect conductor. We are reminded that Prof. Everett, in a recent translation of the works of the author mentioned, assumed that the conductivity of quicksilver in the bulb of a thermometer is the same as a vessel "with thin metallic sides containing water which is stirred" (see Prof. Everett's translation of "Deschanel's Natural Philosophy," Part II., pp. 245-387). The subject is so intimately connected with the determination of solar temperature and solar energy, that it has become indispensable to settle the question by some thorough practical test. Accordingly an apparatus, represented by the following illustration (Fig. 1, p. 266) has been constructed by the writer, to ascertain the conductivity of mercury. Before entering on a description, it will be instructive to point out that the heat communicated to the bulb of a thermometer by solar radiation is transmitted to its contents chiefly by convection, hence that the altitude of the sun during the observation influences the accuracy of the

$$
\text { * NațuRB, vol, v. pp. 344-347. }
$$


indication. This will be readily comprehended. Fig. 2 (p. 267) represents the bulb of a thermometer exposed to the rays when the sun's zenith distance is $65^{\circ}$; Fig. 3 representing the butb when the zenith distance is $18^{\circ} 23^{\prime}$, the latter being the minimum at the Observatory of the Roman College, where the thermoheliometer has been long employed for the purpose of ascertaining the intensity of solar radiation. Referring to Fig. 2, it will seen that the blank crescent $c$, whose varying thickness indicates very nearly the amount of heat imparted at each point of the spherical surface presented towards the sun, occupies a nearly vertical position. The mercury contained within the space indicated by the said crescent, having its specific gravity reduced by the radiant heat, will ascend; while the mercury on the opposite side, which retains its specific gravity, will descend; thus a circulation will be established by means of which the heat received from the sun will be gradually communicated to the entire mass of mercury in the bulb. But, when the latter is exposed to the sun's rays under a zenith distance of about $18^{\circ}$, as shown in Fig. 3, the heated mass of mercury contained within the crescent $a$ has so slight an inclination that scarcely any circulation takes place. Consequently, if it can be shown practically that mercury is incapable of transmitting heat from particle to particle with sufficient velocity, it will be evident that thermometers and thermoheliometers, with spherical bulbs are worthless as means of measuring the intensity of solar radiation. It will be perceived that if the bulb in Fig. 3 be surrounded by an enclosure, as in the thermoheliometer, the mercury contained within the space indi. cated by the crescent $b$ will radiate far less heat towards such enclosure than the mercury within the opposite heated crescent $a$. It will also be perceived that by in.

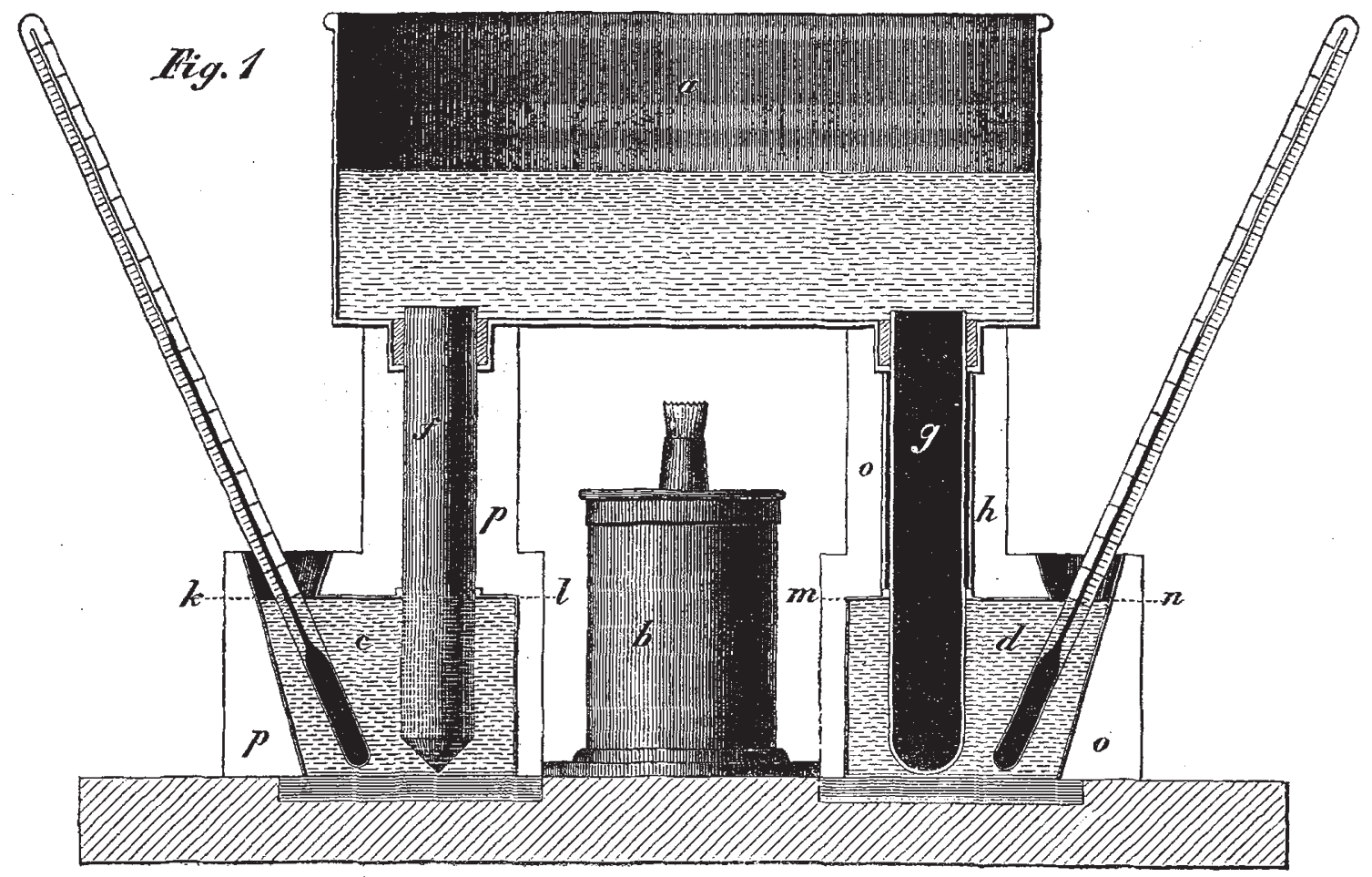

creasing the size of the bulk the transmission of heat from $a$ to $b$ will be retarded unless the conductivity of mercury be perfect. Hence the size of the bulb is an element affecting the accuracy of the indication-a circumstance atal to the employment of a spherical bulb in the thermo heliometer.

The nature of the illustrated apparatus constructed for the determination of the conductivity of mercury will be readily understood from the following description :-Fig. $I$ represents a longitudinal section through the vertical pane, $a$ is a boiler, with a flat bottom and semicircular ends, supported on two columns, $f$ and $g$, resting on the bottom of the cisterns $c$ and $d$. The column $f$ is com. posed of wrought copper plated with silver, highly polished. The column $g$ consists of a cylindrical vessel of glass open at the top, filled with mercury, and surrounded with a socket, $h$, composed of polished silver. The cisterns $c$ and $d$, supported on nonconducting substances, are plated with polished silver, and provided with funnel- shaped openings at the top, through which thermometers are inserted. These cisterns, as well as the columns $f$ and $g$, are surrounded with nonconducting coverings, $p, p$, and $0, o$. A lamp, $b$, is applied behind the cisterns for heating the water in the boiler. It is scarcely necessary to observe that the polished silver plating of the copper column, and the polished silver socket round the mercurial column, are intended to prevent loss of heat by radiation, while the coverings before mentioned are intended to prevent loss of heat by convection attending atmospheric currents. The inside diameter of the cylindrical vessel $g$, it should be noticed, is $0^{\circ} 5$ in., corresponding exactly with the diameter of the copper column $f$, the top of which is on a level with that of the mercurial column. The lines $k l$ and $m n$ are in the same horizontal plane, their distance below the upper ends of the columns $f$ and $g$ being precisely two inches.

The object of the apparatus being that of comparing the conductivity of mercury to that of some other metal 
copper has been selected, as its conducting property is better known than that of any other. The leading feature of the arrangement will be comprehended by a mere glance at the illustration. An equal amount of heat being applied to each column, it is intended to show by the elevation of the temperature of the water in the cisterns $c$ and $d$, what relation exists between the conductivity of mercury and copper. Regarding the application of the heat, it will be evident that an equal amount must infallibly be imparted to each column if the lamp be sufficiently powerful to keep the water in a state of continuous ebullition. Obviously the heat from the lamp, if urged, will cause a rapid upward motion of the water in the middle of the boiler, and a correspondingly rapid descending current at each end. Accordingly lateral currents varying in velocity with the strength of the flame applied under the boiler, will flow inwards over the upper ends of the columns $f$ and $g$.

Several experiments have been made under varying barometric pressures and different atmospheric pressures; but the results as regards the comparative conductivity of mercury and copper have proved to be very nearly alike in all. The accompanying tables record the result of the last trial, conducted as carefully as practicable. The headings of the several columns explain so clearly the object of the tables that it will only be necessary to state that the energy inserted in the fourth column is the energy developed from the beginning of the experiment.

Referring to Table I., it will be seen that at the termination of four minutes from the commencement of the experiment, the temperature of the water in the cistern $c$ had increased $29^{\circ} 06^{\circ}$, the differential temperature being then $212^{\circ}-102^{\circ} 56^{\circ}=109^{\circ} 44^{\circ}$. During the same period a dynamic energy represented by 2.525 thermal units had been transmitted past the line $i k l$, communicated to (I) the water in the cistern ; (2) the part of the copper column immersed; (3) the metal composing the cistern; (4) the immersed part of the thermometer. But, while the entire energy transmitted past the line $k l$, during the four minutes thus amounted to only 2.525 units, the rate of transmission was actually 0.850 unit per minute at the termination of the fourth minute. This apparent discrepancy was caused by the heat absorbed by that part of the column which extends above the line $k l$, the temperature at the commencement of the experiment being the same as that of the surrounding air, $73.50^{\circ}$. Referring to Table II., it will be seen that the energy transmitted through the mercurial column, past the line $m n$, during four minutes, was only 0.087 unit against 2.525 units for the copper column, although the differential temperature of the water in the cistern $d$ was $137.50^{\circ}-109^{\circ} 44^{\circ}$ $=28.06^{\circ}$ higher than in cistern $c$. Accordingly, the conductivity of the copper composing the column $f$ has proved to be $\frac{2.525}{0.087}=29^{\circ} 06$ times greater than the conductivity of the mercury of the column $g$, notwithstanding the higher differential temperature to which the latter was exposed. It will be observed that the glass, $0^{\circ} \mathrm{O} 2$ in. thick, composing the cylindrical vessel which contains the mercury, will conduct some heat downward, tending to increase the temperature in the cistern $d$. This tendency, however, will be balanced by the loss of heat occasioned by the radiation of the glass cylinder, since the application of the polished silver socket and the non-conducting covering cannot wholly prevent the refrigerating action of the surrounding air. It is important to observe, regarding the loss of heat from the latter cause, that the cisterns, previous to trial, are charged with water of the same temperature as the atmosphere. Now, considering that the increment of temperature in the cistern $d$ does not average more than $040^{\circ}$ above that of the atmosphere during the trial, it will be evident that the amount of error caused by radiation will be quite inappreciable. We are therefore warranted in concluding that the conductivity of mercury, determined by the increment of temperature in cistern $d$, and by the dynamic energy transmitted past the line $m n$, cannot be far from correct. It will be asked why columns of such small diameter have been employed. The principal object has been that of presenting a sectional area in the mercurial column $g$, corresponding as nearly as possible to the size of the bulb of an ordinary thermometer. Regarding the dimensions, it will be readily admitted that the conductivity of mercury might have been ascertained with greater exactness, if columns of very large sectional area had been employed; but the trial has conclusively established the fact that mercury transmits heat from particle to paricle too slowly to

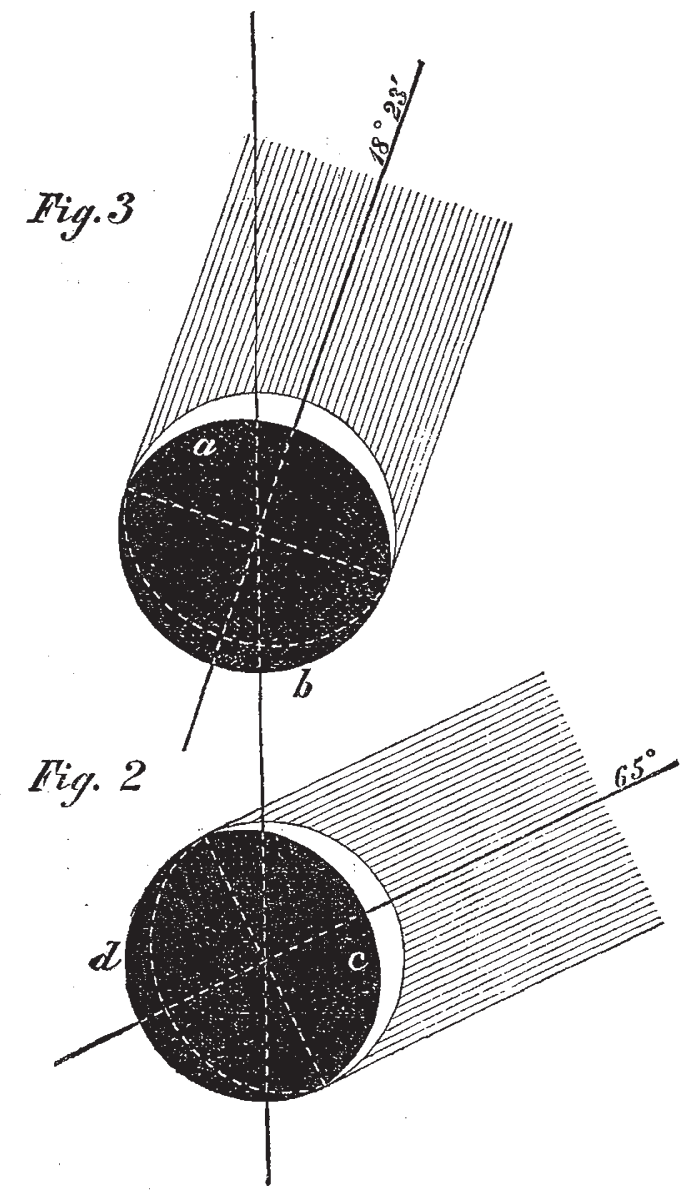

effect a sufficiently rapid indication of mercurial thermometers provided with spherical bulbs; and that, when the heat is applied from above, the indication of such thermometers is wholly unreliable.

A subject of profound interest presents itself in connection with the rate of transmission of energy exhibited in the sixth column of Table 1 . It will be seen that although the copper column $f$ is only 0.5 in. in diameter $=0^{\circ} 19635 \mathrm{sq}$. in. section, the rate of transmission at the termination of the fourth minute is 0.850 unit per minute. Reducing this amount to the usual standard of one square foot, it will be found that the energy developed is

$\frac{144}{0.19635} \times 0: 850=623$ thermal units per minute for a sectional area of I sq. foot. It will be observed that this 
extraordinary amount of energy (theoretically capable of exerting $\frac{623}{42: 7}=14.5$ horse-power) is called forth by the moderate differential temperature of $212^{\circ}-102.56^{\circ}=$ Io9. $44^{\circ} \mathrm{F}$. Now, let us compare the energy of 623 thermal units per minute to that produced by the radiation of a metallic surface coated with lamp black, and maintained at a temperature of $212^{\circ}$, within an enclosure of $102^{\circ}$. Actual trial shows that under these conditions, the radiant energy of a blackened plate composed of copper, containing 144 sq. inches, scarcely reaches 6 thermal units per minute. Otur experiment has therefore established the fact, incidentally, that under the stated conditions, a plate of wrought copper two inches in thickness is capable of transmitting by conduction from one side to the other, in a given time, an amount of mechanical energy more than 100 times greater than the mechanical energy developed by the radiation of the same plate during an equal interval of time.

TABLe I.-COPPER Colum

\begin{tabular}{|c|c|c|c|c|c|c|}
\hline Time. & 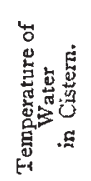 & 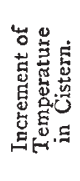 & 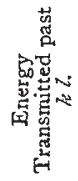 & 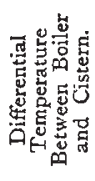 & 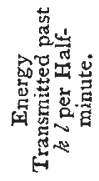 & 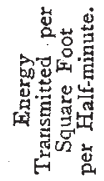 \\
\hline Min. & $\begin{array}{l}\text { Fah. } \\
733^{\circ} 50\end{array}$ & Fah. & $\begin{array}{l}\text { Therm. } \\
\text { Units. }\end{array}$ & $\begin{array}{c}\text { Fah. } \\
138^{\circ} \cdot 50\end{array}$ & $\begin{array}{l}\text { Therm. } \\
\text { Units. }\end{array}$ & $\begin{array}{l}\text { Therm. } \\
\text { Units. }\end{array}$ \\
\hline 0.5 & $75^{-15}$ & $x \cdot 65$ & 0.143 & 136.85 & 0.143 & 104.873 \\
\hline$x^{\circ} 0$ & $77 \cdot 25$ & 375 & 0.326 & $134^{\circ} 75$ & 0.183 & 134208 \\
\hline $1 \cdot 5$ & $80 \cdot 14$ & 6.64 & 0.577 & I 3 I 80 & 0.251 & I84.078 \\
\hline 2.0 & $83 \cdot 84$ & 10.34 & 0.898 & r $28 \cdot 10$ & 0.321 & 235.415 \\
\hline $2 \cdot 5$ & $88 \cdot 14$ & 14.64 & 1.272 & $123 \cdot 80$ & 0.374 & $274 \cdot 284$ \\
\hline 30 & $92 \cdot 81$ & $19 \cdot 31$ & $1 \cdot 678$ & $119^{\circ} 00$ & 0.406 & $297^{\prime} 75^{2}$ \\
\hline $3 \cdot 5$ & 97.67 & 24.17 & $2 \cdot 100$ & $114 \cdot 25$ & 0.422 & $309 \cdot 486$ \\
\hline $4^{\circ}$ & $102 \cdot 56$ & $29 \cdot 06$ & $2 \cdot 525$ & $109^{\circ} 44$ & 0.425 & 311686 \\
\hline
\end{tabular}

TABLE II.-Mercurial COLUMN

\begin{tabular}{|c|c|c|c|c|c|c|}
\hline Time. & 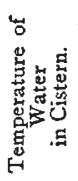 & 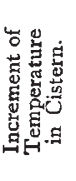 & 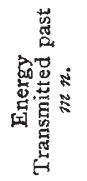 & 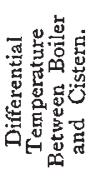 & 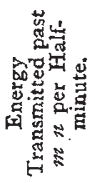 & 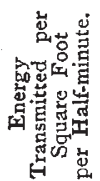 \\
\hline Min. & $\begin{array}{l}\text { Fah. } \\
73^{\circ} 50\end{array}$ & $\begin{array}{c}\text { Fah. } \\
\text { 。 }\end{array}$ & $\begin{array}{l}\text { Therm. } \\
\text { Units. }\end{array}$ & $\begin{array}{c}\text { Fah. } \\
\text { I } 38^{\circ} \cdot 50\end{array}$ & $\begin{array}{l}\text { Therm. } \\
\text { Units. }\end{array}$ & $\begin{array}{l}\text { Therm. } \\
\text { Units. }\end{array}$ \\
\hline 0.5 & 73.52 & 0.02 & 0.002 & 138.48 & 0.002 & $x \cdot 466$ \\
\hline$I 0$ & 73.56 & 0.06 & 0.005 & 138.44 & 0.003 & $2 \cdot 200$ \\
\hline$I \cdot 5$ & 73.64 & 0.14 & o.or 2 & $138 \cdot 36$ & 0.007 & $5^{\circ} 133$ \\
\hline $20^{\circ}$ & 73.75 & 0.25 & 0.022 & 138.25 & o.010 & $7 \cdot 334$ \\
\hline $2 \cdot 5$ & 73.90 & 0.40 & 0.035 & $138 \cdot 10$ & 0.013 & 9.534 \\
\hline $3 \%$ & 74.08 & 0.58 & 0.051 & 137.92 & 0.016 & I I.734 \\
\hline 3.5 & $74 \cdot 28$ & 0.78 & 0.068 & 137.72 & 0.017 & 12.467 \\
\hline $4^{\circ} 0$ & $74^{\circ} 50$ & I & 0.087 & 13750 & 0.019 & 13.934 \\
\hline
\end{tabular}

J. ERICSSON

\section{NOTES}

THE voluminous correspondence connected with the management of Kew Gardens, printed by order of Parliament, was issued at the close of last week. In the debate in the House of Lords on Monday, introduced by Lord Derby, the essential points of the controversy were hardly touched; and pending the debate in the House of Commons on Sir John Lubbock's motion, which was not reached on Tuesday evening, it is obviously pre- mature to enter into the various discussions which are prompted by the contents of the Parliamentary papers.

THE choice of a foreign correspondent of the French Acadénie des Sciences has resulted in the defeat of Mr. Darwin and the election of M. Loewen, of Stockholm, who received 32 votes, against 15 given to the English naturalist. The discussion had extended over three long sittings in secret committee, the leader of the advocates of Mr. Darwin's claim being again his opponent in controversy, M. de Quatrefages, while M. Emile Blanchard led the opposition. A correspondent of Les Mondes, an eminent member of the Academy, in commenting on the result, states that not one of those who voted for Mr. Darwin shared his philosophical doctrines, and not one of those who opposed his candidature alleged as their motive the error or danger of his doctrines. "What has closed the door of the Academy to Mr. Darwin is that the science of those of his books which have made his chief title to fame-the 'Origin of Species,' and still more the 'Descent of Man'-is not science, but a mass of assertions and absolutely gratuitous hypotheses, often evidently fallacious. This kind of publication and these theories are a bad example, which a body that respects itself cannot encourage."

THE subject of Prof. W. K. Clifford's discourse at the ensuing meeting of the British Association will be, "The Aims and Instruments of Scientific Thought." Mr. W. Spottiswoode will deliver a lecture to working men, on "Some Properties of Light, Sunshine, Sea, and Sky."

The Iron and Steel Institute will hold its next meeting in Glasgow, under the presidency of Mr. Henry Bessemer. The reception room will be in the Corporation Galleries, Sauchiehall Street. The general meetings will be held in the Lecture Hall, Corporation Galleries, Sauchiehall Street, as under :- Tuesday, Aug. 6, I.3O P.M., Election of Members, Report of Council to be presented, Papers; Wednesday, Aug. 7, 10.30 A. M., Reading and Discussion of Papers; Thursday, Aug. 8, ro.30 A. M., Reading and Discussion of Papers. A room will be provided in the Corporation Galleries for the exhibition of objects of interest to the trade, either from the neighbourhood of Glasgow or elsewhere. The business proceedings will terminate about 3 o'clock on Tues. day, and it is proposed that members should devote the remainder of the day to visiting the iron and other works in the neighbourhood of Glasgow. A list of these works will be given in the detailed programme to be distributed at the meeting; and a sketch map of the district will also be ready at the same time. On Wednesday, immediately after the conclusion of the business meeting, a special train will be provided to convey the members to Coatbridge and Monkland, where the Gartsherrie, Summerlee, Langluan, Coatbridge, Malleable, and Monkland Iron Works will be inspected. On Thursday, after the conclusion of the general meeting in Glasgow, a special train will be arranged for the Motherwell district, and for the inspection of the iron works in that locality. On Thursday evening, at 7 o'clock, the members will be entertained at dinner, in the Corporation Galleries, Glasgow, by the Local Reception Committee. On Friday an excursion will be made down the Clyde, for the purpose of seeing the industrial features connected with the river. The excursion will also be prolonged to the head of Loch Long, the return being by Loch Lomond to Balloch, and thence by train to Glasgow. Luncheon will be provided at Tarbet. The following papers have been already promised :- "On the Geological Features of the Iron and Coal Districts of Scotland," by Mr. James Geikie, F.G.S., of the Geological Survey of Scotland; "On the Rise and Progress of the Iron Trade in Scotland," by Mr. Jno. Mayer, F.C.S., Glasgow; "On the Differential Clutch for Reversing Mills," by Mr. R. D. Napier, Glasgow ; "On Reversing of Rolling Mills," by Mr. Graham Stevenson Airdrie ; "On an improved form of Squeezer for Blooms produced in 